\title{
Mechanism analysis and protective measures of anti-salt corrosion
}

\section{in concrete}

\author{
Hengchun Zhang ${ }^{1, a}$, Changwen Zhang ${ }^{2, b^{*}}$, Xixian $\mathrm{Ji}^{3, \mathrm{c}}$, Fangyu Tang ${ }^{4, \mathrm{~d}}$, \\ Kaibo Zou ${ }^{5, \mathrm{e}}$, Xiaoqiang $\mathrm{Wu}^{6, \mathrm{f}}$
}

1,2,3,4,5,6 China State Construction Ready Mixed Concrete Fujian Co. LTD, Fuzhou 350000,China.

a115076527@qq.com, bzhangchangwenxs_6636@126.com, ${ }^{c} 290634171 @ q q . c o m$,

d1143396707@qq.com, ${ }^{\text {e wwwzkb@163.com, }{ }^{\mathrm{f}} 59243456 @ q q . c o m}$

Key words: sulfate, chloride, concrete structure, durability

Abstract:The sulfate and chloride has great significant erosion on concrete structure. To provide theoretical reference for practical engineering application, this paper describes the mechanism and influencing factors of concrete sulfate and chloride erosion briefly, then discusses the main measures to improve the salt erosion resistance of concrete by combining the research status.

\section{Introduction}

The corrosion resistance of sulfate and chloride is an important part of concrete durability study. It's the salt solution erosion phenomenon that sulfate and chloride attack which has the largest harmful influence and the most extensive on the concrete durability. The sea, saline-alkali soil, groundwater, sanitary and industrial wastewater all contain a lot of sulfate and chloride in the eastern coastal areas of China., there are more than 1000 saline lakes in northwestern and huge acid rain regions in southwestern. With the development of industry, water pollution has being increasingly serious, leading to the emergence of serious sulfate and chloride salt erosion phenomenon in the concrete engineering. Due to the structural performance degrading of concrete, the concrete engineering have been appeared kinds of mechanical damages without meeting the service year, the phenomenon causes great waste of resources and economic loss. Sulfate erosion may cause the expansion and cracking of concrete while concrete strength and bond behavior all decrease. It is the chloride attack which is the main reason for steel corrosion of the concrete. The passivating film on rebar surface occurs corrosion, even causes the premature failure of concrete structure when chloride concentration of rebar surface above a certain threshold value.

Combining with a large number of materials at home and abroad, the paper discusses the erosion patterns, progress and factors of sulfate and chloride to concrete structure, and states the main measures to improve the concrete salt erosion resistance from sulfate and chloride erosion mechanism, which provide technical reference for practical engineering application.

\section{Mechanism analysis and influencing factors of sulfate erosion in concrete}

The sulfate attack process of concrete and other cement-based materials is a complex physicochemical process that makes slow progress and usually lasts many years. According to 
erosion patterns, sulfate attack of concrete are divided into chemical erosion and physical erosion. Chemical erosion, which refers to volume expansion of ettringite or no gelling hydroxide that reaction of sulfate product, cement hydration products with calcium hydroxide, the corrosion products reduce the alkalinity of cement paste, damage the stably existing condition of C-S-H gel, result in the crack of the concrete expansion; or means that sulfate erosion media take calcium hydroxide corrosion which lead to hydrolysis of cement hydration products. Physical erosion refers to hydrated sulfate crystal that contains crystal water, which is precipitated by reaction of alkali metal sulfate with water in concrete, produce great pressure of physical crystallization, result in the crack of cement-based materials expansion. Comprehensively, the main products of sulfate erosion in concrete include the erosion of ettringite crystal, the erosion of gupsum, the erosion of thaumasite(TSA), the physical erosion of sulfate crystal and the double erosion of $\mathrm{MgSO}_{4}{ }^{[1]}$.

From erosion mechanism, the essence of sulfate erosion in concrete is that the $\mathrm{SO}_{4}{ }^{2-}$ ion in environmental water enter into concrete inner. On the one hand, $\mathrm{SO}_{4}{ }^{2-}$ ion react chemically or physical crystallization with solid components of cement hydration generate the undissolved salt minerals(ettringite, gypsum and so on), for example, ettringite(AFt) and calcium monosulfate aluminate hydrate(AFm) can be converted to one another under certain conditions, induce the change between volume expansion and shrinkage of concrete, then form the internal stress of expansion, lead to corrosion cracking of concrete structure finally. On the other hand, $\mathrm{SO}_{4}{ }^{2-}$ ion which enter into concrete inner dissolve or resolve components of concrete, for instance, $\mathrm{Ca}(\mathrm{OH})_{2}$, C-S-H and others, lead to concrete structure strength and bond behavior all decrease ${ }^{[2]}$.

According to erosion process, influencing factors of sulfate attack in concrete are divided into external factors and internal factors. External factors are test environment of sulfate attack in concrete under the laboratory condition, and service environment of concrete structure under the field test environment. Whether it is the laboratory condition or field test environment, erosion processes are caused by external factors can be broken down into two processes: firstly, infiltration $\mathrm{SO}_{4}{ }^{2-}$ ion from solution of external environment through concrete pore that is the process which is diffused spontaneously from high concentration to low concentration, the diffusion rate determines the impermeability of concrete; secondly, the process that $\mathrm{SO}_{4}{ }^{2-}$ ion reacts with other substances. Erosion processes are caused by internal factors that form expansile compounds physiochemical reaction with sulfate, raw materials of concrete and cement hydrates. Internal erosion directly react with cement hydration products without infiltration from outside, due to it has been existed when concrete is mixed. So the degree of internal erosion is not irrelevant to the diffusion rate of sulfate, but depending on the corrosion content of concrete. The more corrosion contents enter into, the bigger effects of internal erosion have.

Sulfate erosion of concrete always depends on the interaction of many factors. On the basis of sulfate erosion patterns, mechanism and process are comprehensively considered, combining with the erosion of internal factors and external factors, the paper summarize three main influencing factors of sulfate erosion ${ }^{[3]}$ : corrosion solution, self-factors and environmental condition. 


\section{Mechanism analysis and influencing factors of chloride erosion in concrete}

The $\mathrm{PH}$ value of concrete hole solution can reach $12 \sim 13$ thanks to $\mathrm{Ca}(\mathrm{OH})_{2}$ which is produced by the hydration of cement paste. In the high alkaline environment, reinforcement in concrete is in the passivation state has good protection for steel. In the circumstance of concrete on the relatively high chloride concentration while chloride permeate rebar surface in concrete lead to rebar surface passivation state partial or all destroyed as capillarity and free chloride diffusion. Concrete surroundings have proper humidity and oxygen, chloride damage localized steel which lead to electrode potential develop into anode region in the area and others develop into cathode region as the nearby dissolve oxygen exist. The steel bar chemical battery reaction occur with causing rust when electrical conductivity of concrete is small. The chemical constituents of rust is $\mathrm{xFe}_{3} \mathrm{O}_{4} \cdot \mathrm{yFe}_{2} \mathrm{O}_{3} \bullet \mathrm{zH}_{2} \mathrm{O}$, rust of volume is much more expansion than corrosion of reinforcing steel bar, generally for $2 \sim 4$ times the size of the original, so volume expansion produce huge internal stress ( internal stress of expansion reach up to $30 \mathrm{MPa}$ ), and the higher the oxidized degree of the steel bar chemical battery reaction is, the more obvious volume expansion is. The chloride erosion mechanism of steel bar is classified into the following categories ${ }^{[4]}$.

The damage of rebar passivation film in concrete. The $\mathrm{PH}$ value of concrete hole solution can over 12.0 thanks to $\mathrm{Ca}(\mathrm{OH})_{2}$ which is produced by the hydration of cement paste. In the high alkaline environment, there is a compact and strong cohesiveness layer of passivating film on rebar surface, the thickness of layer is $2 \times 10^{-9} \sim 6 \times 10^{-9} \mathrm{~m}$. At present, the parlance of academic circles is different on chemical constituents of the passivating film, some scholars consider that chemical constituents are hydrated oxidation product $\left(\gamma-\mathrm{Fe}_{2} \mathrm{O}_{3} \bullet \mathrm{nH}_{2} \mathrm{O}\right)$, some guess that the major components are covalent oxides-containing silicon, such as, $\mathrm{C}_{2} \mathrm{~S}$ and $\mathrm{C}_{3} \mathrm{~S}$, which contain Si-O bond. Either oxides-containing iron or covalent oxides-containing silicon, the passivating film can be existed stably only in the high alkaline environment. The passivating film doesn't retain a dynamic balance when the surface $\mathrm{PH}$ value of the passivating film drop to 11.8 or lower. On the contrary, the passivating film is gradually being damaged when the steel rebar is in the condition of electrochemical activation. Chloride permeate bar surface in concrete, then a portion of chloride adsorb on the local surface of passivating film, which lead to the $\mathrm{PH}$ value in this area is quickly reduced. At this time, rebar surface exist two erosion patterns that are chemical erosion and electrochemical corrosion. Chemical erosion refers to the chemical reaction that occurs between chloride and bar surface, which has no flowing electrons and occupy a small part of corrosion phenomena. Electrochemical corrosion is that local acidification bar and unspoiled bar form primary battery, then give rise to corrosion phenomenon as primary battery reaction on bar surface. Most of steel corrosion belong to electrochemical corrosion.

The formation of corrosion galvanic cell. The passivating film of bar surface is rapidly being damaged as chloride enter into concrete inner. The chloride damage of the passivating film on bar surface occurs in local spotcorrosion firstly, corrosive solution invade iron substrate of concrete inner. Pittings show iron substrate form the potential difference with intact passivating film in the circumstance of oxygen and moisture. Iron substrate corrosion as anode and a large area of the passivating film as cathode, reaction equation are both in the same reaction rate as follows: 


$$
\mathrm{Fe} \rightarrow \mathrm{Fe}^{2+}+2 \mathrm{e}^{-}
$$

$$
0.5 \mathrm{O}_{2}+\mathrm{H}_{2} \mathrm{O}+2 \mathrm{e}^{-} \rightarrow 2 \mathrm{OH}^{-} \text {. }
$$

The overall reaction let bar surface separate out $\mathrm{Fe}(\mathrm{OH})_{3}$ :

$$
\mathrm{Fe}^{2+}+2 \mathrm{OH}^{-} \rightarrow \mathrm{Fe}(\mathrm{OH})_{2} \text {. }
$$

$$
\mathrm{Fe}(\mathrm{OH})_{2}+0.5 \mathrm{H}_{2} \mathrm{O}+0.25 \mathrm{O}_{2} \rightarrow \mathrm{Fe}(\mathrm{OH})_{3} \text {. }
$$

The effect of primary battery arouse by chloride erosion make bar surface produce serious corrosion pits. Corrosion pits develop rapidly as small cathode area and large anode area while ion substrate form $\mathrm{Fe}(\mathrm{OH})_{3}$ making the reinforcement volume expand six times than the primal. The bar expansion lead to the around concrete exist strong tensile stress. The concrete may produce longitudinal cracks or lead to concrete cover off seriously when tensile stress over concrete tensile strength, accelerating the damage effect of rebar further.

Depolarization. Chloride not only facilitate primary battery erosion of bar surface, but also accelerate erosion reaction of primary battery. Experimental research show that the rebar erosion speed would rapidly increase when the $\mathrm{PH}$ value of erosion solution in concrete inner is less than four. Chloride have the effects of depassivation and depolarization under acidic conditions. $\mathrm{Cl}^{-}$react with $\mathrm{Fe}^{2+}$ to form $\mathrm{FeCl}_{2}$, which break down $\mathrm{Fe}^{2+}$ in concrete hole solution as $\mathrm{FeCl}_{2}$ is soluble, and produce $\mathrm{Fe}(\mathrm{OH})_{2}$ precipitate while meet $\mathrm{OH}^{-}$in diffusion of concrete inner, than transform into iron oxide rust and separate from $\mathrm{Cl}^{-}$, ruduce the content of $\mathrm{Fe}^{2+}$, accelerate the speed of anode reaction. At this time, $\mathrm{Cl}^{-}$only play a transferring role without consumption. The anode depolarization is that $\mathrm{Cl}^{-}$timely remove the anode products and make anode process smoothly or accelerated conduct. It will highly accelerate the corrosion of reinforcement in cycles.

From the operation mechanism of erosion battery, one of factors that erosion battery can be function well is existing free ion channels. The existence of chloride in concrete provide free ion channels that equivalent to improve the corrosion efficiency of erosion battery and accelerate the corrosion process of electrochemistry. In addition, $\mathrm{Cl}^{-}$permeate concrete can react with concrete components and cement paste.

Effects of chloride and cement paste. Under the certain condition, chloride react with $\mathrm{C}_{3} \mathrm{~A}$ produced by cement hydration form insoluble "double salt". The formation of double salt decrease the free chloride content of concrete to some extent, only in the high alkaline environment can double exist stably. Therefore, high content of $\mathrm{C}_{3} \mathrm{~A}$ of cement kinds in favor of resisting the chloride erosion. For example, high content of $\mathrm{C}_{3} \mathrm{~A}$ of ordinary Portland cement is firstly chose during the design process of marine concrete. Besides, chloride may react with $\mathrm{C}_{3} \mathrm{~A}$ to form "double salt" if sulfate exist in hole solution of concrete, which can effectively prevent the reaction between sulfate and $\mathrm{C}_{3} \mathrm{~A}$, reduce the "expansion" damage of concrete. Only in the high alkaline environment can concrete occur that chloride reduce the sulfate erosion effect of concrete to a certain extent. The concentration of sulfate and chloride are relatively high, which may accelerate concrete erosion and steel corrosion.

\section{The main measures of anti-sulfate and anti-chlorine corrosion}

The main measures of improving sulfate resistance. Sulfate erosion of concrete have external 
factors and internal factors, both of which are taken improvement of the anti-sulfate into account. On the basis of ensuring working capability and mechanical property, adopting methods of combing matrix measures with external factors to estimate pros and cons of anti-sulfate measures synthetically.

Improving the types of cement to reduce components of poor corrosion resistance. Different cement types concoct different the anti-sulfate erosion of concrete. The mineral components of portland cement clinker include $\mathrm{C}_{3} \mathrm{~S}, \mathrm{C}_{2} \mathrm{~S}, \mathrm{C}_{3} \mathrm{~A}$ and $\mathrm{C}_{4} \mathrm{AF}$. The relative quantity of those four mineral have great influence on the anti-sulfate erosion ability of concrete, especially the contents of $\mathrm{C}_{3} \mathrm{~A}$ and $\mathrm{C}_{3} \mathrm{~S}$. Some studies ${ }^{[5]}$ indicate that accelerate the formation rate of the hydrated calcium aluminate and significant increase the formation of ettringite as the increase of $\mathrm{C}_{3} \mathrm{~A}$ content. That vast $\mathrm{Ca}(\mathrm{OH})_{2}$ is precipitated by the hydration of $\mathrm{C}_{3} \mathrm{~S}$ are essential components to form gypsum. Therefore, the contents of ettringite and gypsum can be reduced while decrease the contents of $\mathrm{C}_{3} \mathrm{~A}$ and $\mathrm{C}_{3} \mathrm{~S}$ of cement clinker, effectively inhibite ettringite crystal erosion and gypsum crystal erosion. Furthermore, instead of cement, mineral admixtures can also improve the ability of the anti-sulfate erosion in concrete. Some mineral admixtures have been studied at present, such as fly ash, granulated blast furnace slag, volcanic ash, beads, superfine silica fume, zeolite powder, limestone powder and so on. The double mixed admixture and combined admixture, each of which mix with superplasticizer, allocating low water binder ratio of concrete. It not only decrease the contents of $\mathrm{C}_{3} \mathrm{~A}$ and $\mathrm{C}_{3} \mathrm{~S}$ of cement clinker, but also occur secondary hydration reaction with cement hydrates $\mathrm{Ca}(\mathrm{OH})_{2}$, decreasing the content of $\mathrm{Ca}(\mathrm{OH})_{2}$ in cement pastes. Besides, the gel production with tiny structure fill the pores of cement pastes, then improve the resistance of sulfate erosion properties in concrete. That literatures ${ }^{[6]}$ have introduced systematic and sufficient study on adopting mineral admixtures to enhance the resistance of sulfate erosion abilities in concrete. Soking the concrete samples in the concentration of $3000 \mathrm{mg} / \mathrm{L}$ of sodium sulfate or magnesium sulfate. Ten years later, concrete don't have any damage until the content of mineral admixtures reach $42 \% \sim 72 \%$ in concrete. On the contrary, mineral admixtures in 3.5\% 12.3\% content of cement product concrete samples all have different degree of damage in the same erosion solution and ages.

To improve intensity of concrete, we need to design mixture ratio reasonably and decrease waterbinder ratio. The main measure is controlling water-binder ratio in respect of improving concrete density. Studies show that water demand of cement hydrates occupy $15 \%$ of cement quality, but the practical water consumption account for cement quality more than $40 \% \sim 60 \%$. Connected pores are formed by the extra moisture that evaporate or flow in particles of concrete components, which equivalent to provide the channel that sulfate erosion mediun permeate inside the concrete, then accelerate the speed of sulfate erosion. So we must control water consumption strictly when we design the resistance of sulfate erosion in concrete. That adding superplasticizer and superfine mineral admixture to decrease water-binder ratio can reduce the pore structure of concrete and crease concrete compaction. Previous studies suggest that water-binder ratio of concrete is smaller, the binder-sand ratio and size is bigger. Furthermore, the slower flexural strength and bending strength decrease, the larger capacity of the anti-sulfate erosion of concrete have.

To add protective coating in vulnerable areas. At present, the hot fields of research on concrete 
corrosion resistance is using protective coating, which is brushing protective coatings on concrete surface. That coatings permeate inside the concrete may form water-repellent layer in a certain depth, or close surface pores and defects to prevent the incursions of moisture and harmful substance. The Japanese make an experiment on restraining concrete erosion of coatings in Tokyo Bay, and it is seven years that coatings have no corrosion which is compared with uncoated layers that the erosion area of uncoated layers has achieved $80 \%$.

Besides, immersion ways and curing condition also affect the results of the resistance of sulfate erosion. For example, comparing with ordinary curing condition, high — pressure steam curing is much easier to remove free $\mathrm{Ca}(\mathrm{OH})_{2}$, and the crystal hydrates of $\mathrm{C}_{2} \mathrm{~S}$ and $\mathrm{C}_{3} \mathrm{~S}$ is more stable than the $\mathrm{C}-\mathrm{S}-\mathrm{H}$ in normal temperature. That the hydration of $\mathrm{C}_{3} \mathrm{~A}$ produce $\mathrm{C}_{3} \mathrm{AH}_{6}$ with low-level constitutive activity entirely improve the properties of anti-sulfate.

The main measures of improving chloride resistance in concrete structure. There are many factors for affecting steel corrosion, which is broadly divided into internal factors and external factors. Internal factors include cement types, the content of chloride in sand stone materials, the thickness of covering layer, the location and diameter of rebar, the composition of internal pore solution and so on. External factors contain temperature, humidity, corrosion environment, the effect of circulating heating and cooling in the surroundings. In view of these influence factors, we should adopt actual measures to improve the chloride corrosion resistance of concrete. Nowadays, more methods on research are using high-performance concrete, reinforcing bar rusty retardant agent, special reinforcing steel, technology of surface treatment, cathode protection and so on. Building a detailed kinetic model of chloride erosion in concrete under coupled effects of multifactors. That based on the experimental data, modeling the overall process is new trend of studying chloride erosion in concrete at present.

The content of chloride in concrete have great impact on steel corrosion, chloride incursion is an important cause of steel depassivation and steel corrosion of concrete. We need to strictly control the chloride content of raw materials in the process of the preparation of concrete. Choosing raw materials with the chloride content is satisfied, and through greatly reduce water-binder ratio to improve the pore structure and interface structure of concrete, enhancing the anti-chlorine corrosion of concrete. Yang $\mathrm{Yi}^{[7]}$ has studied the phenomenon that single-added or combined admixture with adding different content of fly ash, ground slag and silica fume produce the chloride erosion of high performance concrete in the case of low water-binder ratio. For high performance concrete with fly ash single mixed, increasing the content of fly ash while the resistance to chloride permeability of concrete significantly is enhancing. The resistance to chloride permeability of concrete begin to decline as the content is above $50 \%$.

As an anticorrosion admixture, reinforcing bar rusty retardant agent has abilities on weakening activation performance of rebar and preventing chloride from damaging deactivated film of reinforcing bar. Reinforcing bar rusty retardant agent are classified with chemical constituents may divided into inorganic, organic and mixed type. Research shows that FAC-13 reinforcing bar rusty retardant agent have no obvious influence on working capability, compressive strength and relative dynamic elasticity modulus, but the diffusion coefficient of chloride in concrete, steel bar corrosion 
ratio and weightlessness rate is significantly reduced. It shows that reinforcing bar rusty retardant agent can significantly enhance the chlorine erosion resistance of concrete. The new migrating corrosion inhibitor with nontoxic, environmental protection and green is becoming a hotspot in the field of reinforcing bar rusty retardant agent.

Ordinary Q235R steels have poor capability on resisting chloride erosion, but special reinforcing steels which are produced by quenching, normalizing, tempering, and annealing, then adding W, Mn, $\mathrm{Cu}, \mathrm{Zn}$ and other elements can be used in concrete to greatly improve the durability of reinforced concrete. At present, special reinforcing steels include galvanized rebar, corrosion resistant bar, stainless steel rebar and synthetic materials etc. Weathering steel exploited by the Japanese which has better corrosion resistance than plain steel in the marine atmosphere, demonstrating the superiority of anti-chlorine corrosion of special reinforcing steels.

Surface treatment technology is another important protection measures of anti-chlorine corrosion, which help adding a resistant coating, preventing acid or alkali from damaging concrete, delaying steel corrosion. Present study on the anti-corrosion coating are two types: one model which is the study on rich zinc anti-corrosive coating, the other model which is the study on epoxy anticorrosive coating. Canada and the United States are the earliest countries to use rebar with epoxy coating, many concrete defence engineerings in Europe also use epoxy anti-corrosive coating. The most representative was that Denmark used epoxy anti-corrosive coating in the Great Belt tunnel project in 1990 .

Under the influence of cathode current, cathodic protection is that the protected rebar entirely in the state of cathodic without corrosion, which is an effective method of electrochemical protection, and usually be used in many concrete engineerings, such as, underwater, underground metal pipe, steel pipe pile and offshore platform etc. According to different protection methods, cathodic protection method can divided into impressed current cathodic protection method and the cathodic protection method with sacrificing anodes. Degiorgi ${ }^{[8]}$ has demonstrated a way to solve potential distribution of cathodic protection system of hull plate as the anode to boundary conditions in a constant potential value, obtaining a steady potential at a particular moment and a certain level of anode current.

\section{Conclusions and prospects}

Sulfate erosion and chloride erosion severely impact the durability and safety of concrete. Sulfate erosion is statistically relative to the erosion solution, factors of concrete, environmental condition, etc. Improving anti-sulfate corrosion which not only need to decrease the components of poor corrosion resistance of raw materials, but also synthesizes mixture proportion, curing conditions, surface treatment technology, etc. Chloride erosion mainly occur corrosion on the reinforcing steel bar. Previous research has shown that using reinforcing bar rusty retardant agent of high performance concrete, special reinforcing steel, surface treatment technology and cathodic protection technology can significantly improve the ability of anti-chlorine corrosion in concrete.

Nowadays, numerical simulation technology as a new research area begins to utilize in the aspects of anti-sulfate and anti-chlorine corrosion in concrete. This technology is that using a 
numerical approach, and combining with finite element analysis to solve every anti-corrosion model to carry the point of efficiently improving the ability of anti-sulfate and anti-chlorine corrosion. The proportion of mineral admixtures, the proportion and kind of preservatives, reinforcing bar rusty retardant agent, coating protection and cathodic protection as the main factors of the numerical simulation, giving the degree of anti-sulfate and anti-chlorine corrosion in concrete by numerical calculation and image display to comprehensively assess cost-effectiveness and anti-corrosion effect. The damage of anti-sulfate and anti-chlorine corrosion is decreased to minimum. At present, numerical simulation technology in the aspect of anti-sulfate and anti-chlorine corrosion is under trial, corrosion protection measures and finite element model still need to further research and demonstration.

\section{References}

[1] Yang Benju. Experimental study on preservatives of anti-sulfate corrosion of concrete[D]. Qingdao Technological University, 2011(In Chinese).

[2] Rafael Talero. Performance of metakaolin and Portland cements in ettringite formation as determined by ASTM C 452-68: kinetic and morphological differences[J], Cement and Concrete Research 35(2005): 1269 1284.

[3] Shi Yunxing et al. The formation and stability conditions of ettringite[J], concrete, 2000. (8): 15 to 19 (In Chinese.

[4] Fu Fei. The invasive research on resistance to chloride iron of bridge pile foundation of high performance concrete [D]. Southwest Jiaotong University, 2009(In Chinese).

[5] Omar Saeed Baghabra Al-amoudi. Sulfate attack and reinforcement crrosion plain and blended cements exposed to sulfate environments[J], Building and Environment, 1998, 33(1): 53-61.

[6] W.A.Tason. Influence of Ground Granulated Blast furnace Slag on the Sulfate Resistance of Lime-Stablilized[J]. Magazine of Concrete Research, 1997, 51(4): 247 254.

[7] Yang Yi, Tong Zhangfa, Feng Qingge et al. The permeability of resistance to chloride ion of high-performance concrete with large charge[J]. Journal of Wuhan university of technology. 2010, 32 (15): 9-12(In Chinese).

[8] Degiorgi.V.G, Wimmer.S.A. Geometric details and modeling accuracy requirement for shipboard impressed current cathodic protection system modeling[J]. Engineering Analysis with Boundary Elements, 2005, 29:15-28. 